\title{
The North Norfolk Coastline: A Complex Legacy
}

Ruth Brennan

School of Earth, Ocean and Environmental Sciences University of Plymouth, Plymouth, England

This is the accepted manuscript of a paper originally published in Coastal Management. You may find the final, formatted version at 10.1080/08920750701593428.

\section{Abstract}

The North Norfolk coast is a naturally eroding coastline that has been subject to various management strategies over time, many of which have impeded its natural evolution. The Kelling to Lowestoft-Ness Shoreline Management Plan underpins management of the North Norfolk coast, advocating policies of managed realignment and no active intervention for much of this coastline. Implementation of these policies would give rise to significant loss of housing in North Norfolk during the course of this century. This has caused intense conflict between local communities and coastal planners, with the former feeling abandoned to the vagaries of natural coastal processes. Coastal planners need to work closely with local communities to implement a long-term vision for a sustainable coast. The issues of conflicting land-use planning policies and compensation for affected communities must be addressed. The wider implications of current management strategies are not fully understood and may, in some cases, be unsustainable.

\section{Introduction}

Historically, coastal zone management in England and Wales was characterized by a fundamental lack of understanding of natural coastal processes and a view of the boundary between land and sea as fixed rather than dynamic (Coates et al., 2001). The emergence of a new management ethos over the past two decades has been driven by a change in environmental attitudes and values (Hooke, 1998) and an appreciation of the role of the longterm evolution of the coast in identifying sustainable management strategies (Burgess et al., 2002). This new ethos has found concrete expression in the movement away from "hard" engineering solutions to coastal defense problems toward a "softer" approach, evidenced by the development and adoption of a policy of working with natural processes (Hooke, 1998). An emphasis on adaptive management techniques and stakeholder engagement in coastal management decisions is also increasingly evident.

For the past decade, Shoreline Management Plans (SMPs) have underpinned coastal defense planning in England and Wales. These non-statutory plans (which are developed by coastal planners on a local, regional, and national level) provide a large-scale assessment of the risks associated with coastal processes and present a long-term policy framework to reduce those risks to people and the developed, historic, and natural environment in a sustainable manner 
(DEFRA, 2006a). The aim of the SMP is to identify future policy that is technically and environmentally sustainable and economically viable (Burgess et al., 2002) and to produce a map of the coast showing for different "policy units" which of the following four shoreline management policies are recommended: (i) hold the existing defense line; (ii) advance the existing defense line; (iii) managed realignment; and (iv) no active intervention (DEFRA, 2006a).

The first generation of SMPs (completed in 1995-2000) primarily focused on contemporary hydrodynamic and sediment transport processes (Burgess et al., 2002). These SMPs have been criticized for their failure to appreciate the long-term evolution of the coastline and the implications of future sea-level rise and climate change (MAFF, 2000). The Futurecoast (2002) research project addressed these criticisms by identifying the different elements that make up the coastal structure and developing an understanding of how these elements interact and respond over different spatial and temporal scales (Burgess et al., 2002). This research recognized that it is the interaction between different geomorphologic units that determines coastal behavior and that feedback between such geomorphologic units plays a crucial role in this process (Murdock et al., 2001, Burgess et al., 2002; Cooper \& Jay, 2002). The Futurecoast project has informed the latest policy guidance (DEFRA, 2006a) for a second generation of SMPs (which should be completed by 2010). This guidance was released under the new "Making Space for Water" strategy for flood and coastal erosion risk management (formulated by the Government's Department for Environment, Food and Rural Affairs (DEFRA)) which envisages more flood and coastal erosion solutions working with natural processes (DEFRA, 2006b).

Protection of the North Norfolk coastline predominantly dates from the early 20th century (ACAG, 2005). It is a relatively recent phenomenon in light of the fact that this coastline has been retreating for millennia. A profound lack of appreciation of the natural processes operating along the North Norfolk coastline has (mis)informed a plethora of management decisions relating to protection of this coastline from erosion. This has created a complex and challenging legacy to manage, especially in the light of potential future climate change, sealevel rise and natural coastal change (DEFRA, 2006a). The growing recognition (on the part of coastal planners) that coastlines are inherently dynamic areas and that therefore it is unrealistic to expect to maintain the coastline in all places as it is now (DEFRA, 2006a) is not shared or understood by the majority of the general public. This has led to communities such as the inhabitants of Happisburgh in North Norfolk, with homes and/or livelihoods threatened by coastal processes, feeling abandoned and cheated by the UK government and powerless in the face of such natural processes (Figure 1). The lack of local community engagement in the coastal management process, contradictory land-use planning policies (on local, regional, and national levels) and failure to address the issue of compensation for coastal dwellers facing relocation have contributed to widening disparities in understanding between coastal planners and affected communities and illustrate an urgent need for the Government to revisit its policies and practices in these areas.

This article discusses the conflicts inherent in the proposed shoreline management strategies for North Norfolk, the management challenges posed by its natural coastal processes and its inhabitants (human and wildlife) and the part played by current Government policy in hindering 
the effective tackling of these issues. The aim of this article is to identify the changes needed in relation to management strategies and Government policy and practice to resolve the coastal management issues evident in North Norfolk. As the North Norfolk coastline represents a microcosm of current coastal zone management issues in England and Wales, the analysis provided by this article should also prove useful in a wider context.

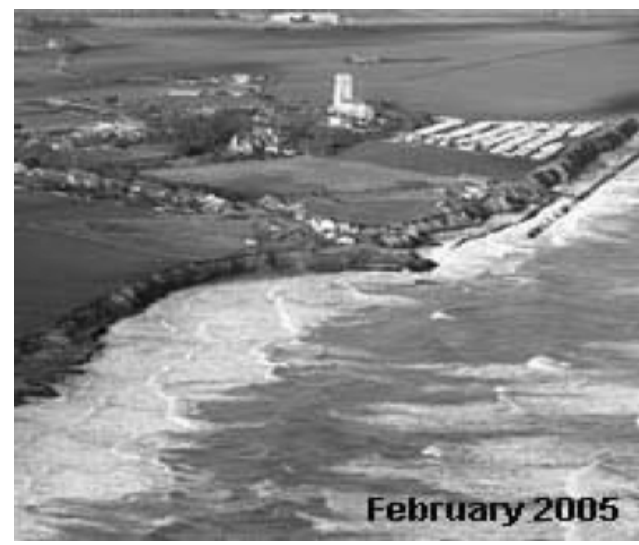

Figure 1. "Happisburgh is being abandoned!" (CCAG, 2006).

\section{The North Norfolk Coastline}

\section{Natural Coastal Processes}

The North Norfolk coastline (Figure 2) is highly dynamic and geomorphologically diverse, consisting of consolidated and unconsolidated soft-rock cliffs, offshore barrier beaches and salt marshes protected by sand dunes and shingle banks (Bridges, 1998). Erosion is, and has for centuries been, occurring along this retreating coastline. Similarly, coastal flooding has been a common occurrence in the past (ACAG, 2004).

There are several different erosional processes operating along this coastline. Erosion and retreat of the almost vertical Hunstanton cliffs to the north is the result of a combination of undercutting by wave-action leading to collapse of the well-jointed consolidated rock from the cliff-face (Bridges, 1998). In contrast, erosion and retreat of the more gently- sloping, cliffs to the north-east (from Weybourne to beyond Happisburgh) is due to the unstable cliff-face collapsing in landslips and mudflows (Bridges, 1998). As these north- eastern cliffs are not in equilibrium with the forces eroding them, the process repeats itself, giving rise to a rapidly retreating coastline (Bridges, 1998). The removal of this material by longshore transport (and its subsequent deposition along the coast) explains the presence of well-developed beaches along an otherwise eroding coast (Bray et al., 1997).

\section{Present and Future Coastal Protection Strategies}

The perceived need for protection of the North Norfolk coastline has its origins in human desire to resist and control the natural coastal process of erosion, which poses a threat both to property and important natural habitats. This desire to control the natural environment is evident from the array of site-specific and piecemeal "hard" engineering defenses along the coast, which houses a plethora of sea-walls, groynes, revetments, and rock armor. 
The pilot second-generation Kelling to Lowestoft-Ness SMP defines the proposed coastal protection strategy for the section of North Norfolk coastline stretching south-east of Sheringham (see Figure 2) as far as Lowestoft-Ness where the North Suffolk coastline begins (ACAG, 2004). It displays a concerted effort to move away from maintenance and replacement of the "hard" engineering defenses described earlier and instead to adopt, where possible, a more holistic management strategy that works in harmony with the natural coastal processes. An example of this "softer" management approach is the strategy of managed realignment, which is the deliberate process of realigning coastal defenses; it may involve breaching existing defenses to allow flooding, or removing existing defenses to allow erosion up to a new defense line (Brooke, 1992; Ledoux et al., 2005). The Kelling to Lowestoft-Ness SMP advocates managed realignment or no active intervention along much of the North Norfolk coastline in the medium to long-term, with a long-term strategy to hold-the-line only applying to key areas of economic importance and residential and commercial developments (Sheringham, Cromer, Great Yarmouth, Gorleston, and Lowestoft). Elsewhere (Overstrand, Mundesley, and Caister, for example), the SMP proposes to continue the hold-the-line policy in the short-term only, giving way to the preferred strategy of managed realignment or no active intervention in the medium and long-term.

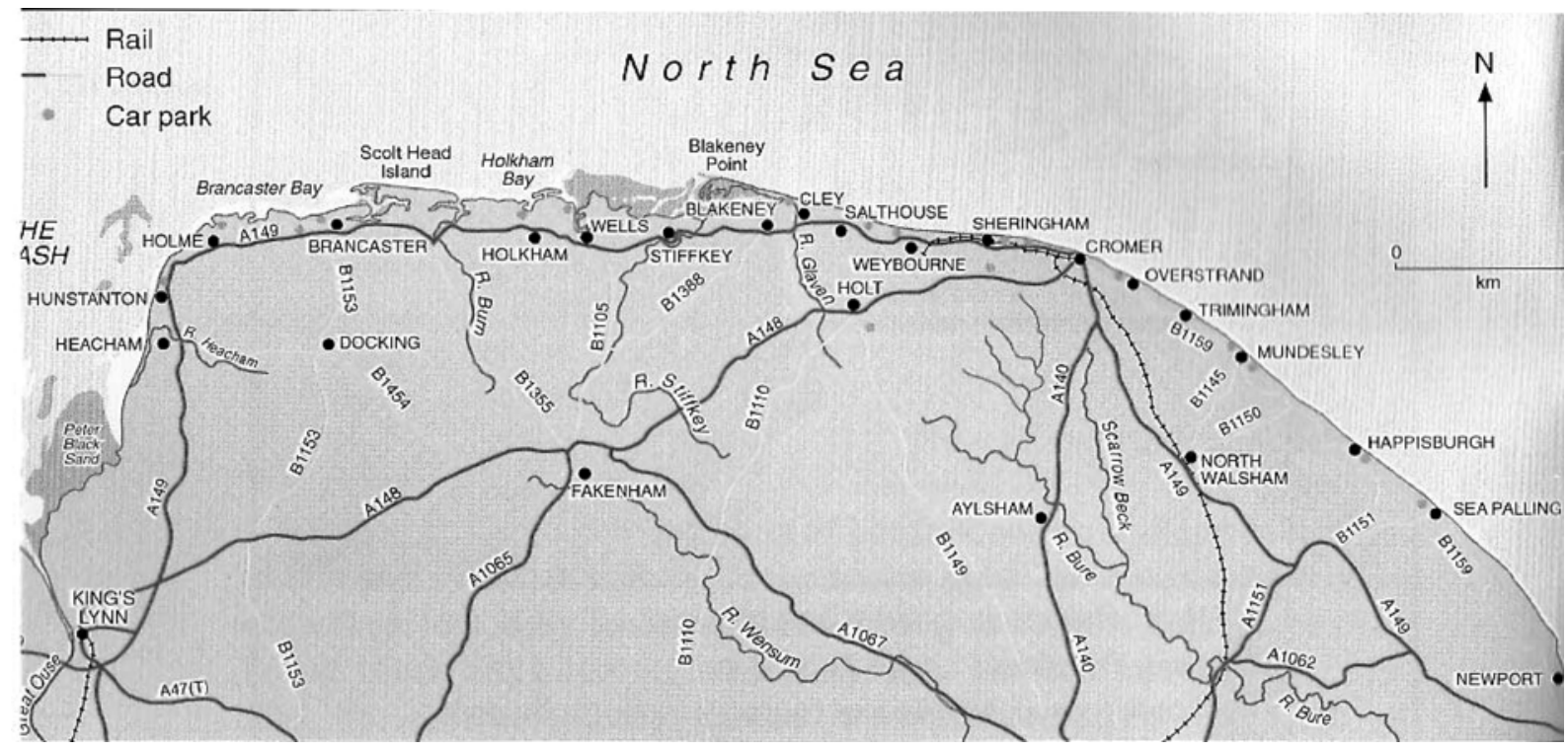

Figure 2. The North Norfolk coastline (Bridges, 1998)

\section{Managing Natural Changes}

\section{Development vs. Natural Processes}

The root of the many shoreline management problems encountered in North Norfolk is the fact that, from Kelling to Lowestoft-Ness, the coastline represents a single littoral-drift system (ACAG, 2004). Coastal development necessitates defense that can have knock-on effects leading to the loss of other coastal areas, for example by preventing longshore sediment movement and thus starving downcoast beaches (French, 2004). An example of this along the North Norfolk coastline can be found at Overstrand: the section of cliffs from Cromer to 
Mundesley provides a vital source of sediment for the beaches to the south. However, the seawall, timber groynes, and revetments at Overstrand have already resulted in a significant promontory forming that blocks sediment transport and supply to downcoast beaches. It may also cause a net loss to the system as sediment is moved offshore more rapidly (ACAG, 2004). At the same time, the coastline from Overstrand to Mundesley houses a large number of socioeconomic/human assets that would be at risk should the coastline retreat through the natural processes of erosion. Due to this conflict, the proposed initial short-term strategy is to maintain defenses at Overstrand until techniques to manage and mitigate losses to coastal communities are developed, although the sea-wall would not be rebuilt should it fail during this time. The proposed medium and long-term strategy is one of managed realignment (ACAG, 2004).

Similarly, the sediment feed from cliff erosion between Gorleston and Hopton is vital to feed beaches and enhance protection along this coastline, especially in light of the fact that sediment feed from the north is limited by the current coastal defenses impeding longshore transport of sediment (ACAG, 2004). Conflicts are again evident: allowing the coastline to retreat naturally between Gorleston and Hopton through the proposed strategy of no active intervention would result in erosion of Gorleston golf course, eventually culminating in the loss of an important recreational and tourist amenity.

\section{Sustainability and Ecological Issues}

The North Norfolk coastline is home to a diverse range of habitats, including salt marsh, intertidal flats, dunes, shingle, and freshwater grazing marsh. The many national and international designations along the coastline reflect the high conservation value of such habitats (Myatt-Bell et al., 2002). The non-designated sections of coastline often reveal the application of management strategies without due regard for their wider implications, in particular their sustainability. Paradoxically, the consideration of such wider implications in designated areas of coastline can be equally detrimental to effective management.

Managed realignment and salt marshes. Ledoux et al. (2005) noted that, although managed realignment projects are understandably more complex than "classical" defense schemes, case studies show that they are becoming increasingly costly and time-consuming. It must also be recognized that managed realignment is not the solution to all coastal problems and it is important to question its sustainability (French, 2004). Blackwell et al. (2004) point out that the practice of managed realignment is being promoted without a full understanding of the wider implications for both the managed realignment sites themselves (such as salt marshes) and the

wider environment. Several studies carried out on the salt marshes of North Norfolk have called into question the sustainability of using these landforms as natural sea defenses. Mo"ller et al. (2001) (in a study carried out on Stiffkey salt marsh) emphasized that sustainability of this defense must be examined over different time-scales so that marsh erosion and accretion can be taken into account.

Hold-the-line, coastal steepening, and coastal squeeze. Research carried out by Taylor et al. (2004) shows that the majority of the coastline of England and Wales has steepened over the 
last century, with much of the East Anglian coastline experiencing the greatest degree of change. The phenomena of both coastal steepening and coastal squeeze call into question the sustainability of the hold-the-line management strategy. For example, where there is a sea wall, this static defense prevents the coastal system from naturally retreating landward, narrowing the intertidal zone and adversely affecting coastal zone habitats (Taylor et al., 2004). An example of this is the Beeston cliffs Site of Special Scientific Interest at Sheringham where the current and proposed management strategy of hold-the-line (in the short, medium, and long term) may result in loss of protected cliff-top habitats due to coastal squeeze as the sea-wall will prevent these habitats from rolling back with the cliff line (ACAG 2004).

The Habitats Directive. The Conservation (Natural Habitats) Regulations 1994 (the Regulations) represent the UK's transposition of the Habitats Directive (92/43/EEC) into UK law. The Regulations require compensation for a displaced habitat by recreating an equivalent or different habitat elsewhere. This restrictive interpretation of the Habitats Directive can hinder effective coastal management designed to work in harmony with natural processes, as it is costly and time-consuming to administer (Ledoux et al., 2005). This is evident from much of the Kelling to Lowestoft-Ness SMP which, on several occasions, notes that the preferred management strategy cannot be implemented until further research is carried out to investigate the effects on affected habitats. For example, the Winterton Dunes National Nature Reserve (which forms part of the Winterton-Horsey Dunes Site of Special Scientific Interest and candidate Special Area of Conservation) is currently protected by a sea-wall. There is uncertainty as to how the dunes would respond if the sea-wall were lost-it is possible that they would be eroded and lost rather than rolling back. The long-term preferred strategy of managed realignment in this area is not possible until further research on beach-dune response is carried out (ACAG, 2004).

\section{Adaptive Management}

The uncertainty surrounding the fate of the Winterton Dunes National Nature Reserve illustrates the challenge posed by the ecosystem approach to management: to manage activities within the boundaries of dynamic, unpredictable, and adaptive ecosystems and social systems (Walker et al., 2002; Mee et al., 2005). Adaptive management, which has its roots in the ecosystem approach, attempts to increase resilience to unforeseeable change in an ecosystem and recognizes that the level of scientific uncertainties in social and ecological systems can often prevent the making of long-term management decisions (Mee et al., 2005). The adaptive management process involves (i) an agreed long-term vision for the future state of the ecosystem; (ii) establishment of pragmatic shorter-term operational objectives; (iii) progress review by monitoring; and (iv) information feed-back loops. As research reduces uncertainty, the process begins again and the operational targets (and long-term vision) may be revised (Mee et al., 2005).

For now, the chosen vision for the Winterton Dunes National Nature Reserve is protection of the dunes. A future vision may recognize that protected habitats, like people, must accept that the coastline is a dynamic environment and that their position in that environment is not guaranteed. Indeed, the mid-1990s saw such a vision being implemented (albeit not through 
stakeholder consensus) on the North Devon/Somerset coast in the south-west of England when the Porlock gravel barrier was breached by a succession of storms. The breach left the land behind the barrier flooded, resulting in the loss of a freshwater lagoon (a protected Site of Special Scientific Interest) but recreating a saline lagoon and tidal habitats. The barrier is now being studied as it evolves naturally (Orford \& Jennings, 1998). More recently, in South Devon, DEFRA has adopted a policy of implementing "small-scale protective measures coupled with a long-term adaptation programme" in relation to the coastal road running alongside the Slapton Sands shingle beach as it is not economically or environmentally feasible to defend the road from future erosion (http://www.defra.gov.uk/environ/fcd/policy/strategy/sd7/sld2317.htm). Illustrating adaptive management techniques (and perhaps lessons learned from Porlock), a key feature of the current 3-year management project is the support and engagement of the local community in the running of the project (http://www.slaptonlinepartnership.co.uk/).

The Kelling to Lowestoft-Ness SMP provides an excellent framework for the adaptive management process as it proposes management strategies on a variety of temporal and spatial scales. However, the close involvement of all stakeholders, which is crucial to the success of the adaptive management process (Walker et al., 2002; Mee et al., 2005; Lane \& McDonald, 2005), is noticeably absent in North Norfolk. The failure to properly involve affected communities in the development of the SMP has been instrumental in the lack of local acceptance of many of the short-, medium, and long-term policies proposed for the region.

\section{Conflicting Visions}

\section{Failure to Engage Local Communities}

Community-based environmental planning and decision-making, whereby authority and resources are devolved to local communities for the purposes of environmental management and planning, can enhance the understanding of local communities by bringing them closer to the problem, enable a more sophisticated understanding of the local social and physical environment and facilitate more effective plan implementation by including locals in their development and implementation (Lane \& McDonald, 2005). It is, however, overly simplistic to view community-based participation as a move from a "top-down" to a "bottom-up" management approach. Central government agencies and local communities act at different political scales so that "environmental management, policy and practice occur, at any moment, somewhere along a sliding (even slippery) scale that ranges from the local to the central" (Lane \& McDonald, 2005). Furthermore, too much emphasis on particular stakeholder interests can exclude the general public interest from being taken into account (Lane \& McDonald, 2005).

The managed realignment and no active intervention policies that have been recommended by the Kelling to Lowestoft-Ness SMP for much of the North Norfolk coastline have obvious implications with regard to the need to relocate communities away from "at risk" areas. In its recent program update report to its Making Space for Water strategy (DEFRA, 2007), DEFRA has described the status of various on-going projects by which it is trying to help such communities adapt to the changing coast. However, the formation of coastal groups by local communities 
highlights a lack of meaningful involvement in the decision-making process. The Coastal Concern Action Group (CCAG; which represents the views of the Happisburgh community) strongly resists the proposed policy of no active intervention for Happisburgh and feels that that its submissions and concerns have been "sorted, analysed ... categorised ... and ignored" by local and central government bodies (CCAG, 2006).

In contrast, the Felpham Sea Defence Committee in West Sussex is an example of the advantages of meaningful local community participation in decision-making: Felpham is completely dependent on coastal defenses, yet the dialogue established (between academics, engineers, local authorities, and the general public) by its Sea Defence Committee generated a surprising consensus among the local community for a holistic, geographic, systems approach to facilitate conservation of near-shore sediment and minimize structural interventions (Bray et al., 1997).

Although the efforts on the part of the authorities to consider and respond to the concerns of local communities in North Norfolk (as evidenced by the December 2005 Response to Consultation (ACAG, 2005)) are encouraging, it is arguable that some of the responses have served only to incense the local communities: for example, in response to concerns raised as to the loss of historical buildings (such as the Lutyens buildings in Overstrand), the Response to Consultation counters that "defence of this coast dates predominantly from the 20th century and so the process of erosion could be considered to form an important aspect of the area's history and heritage." It is one thing to argue that erosion is part of the natural coastal processes that have been on-going for centuries; it is quite another (given the sensitivity of the subject) to submit that erosion should be welcomed as part of an area's history and heritage. Such a comment arguably does more harm than good where acceptance of the management strategy by the local communities is concerned.

DEFRA's on-going Stakeholder and Community Engagement project to improve stakeholder engagement in risk management at local, regional, and national levels (DEFRA, 2007) recognizes the importance of local communities feeling that, difficult and unwelcome though some of the current and proposed management decisions may be, these decisions "belong" to the local communities and are merely being implemented by the relevant authorities. However, the consultation process in North Norfolk to date has involved a series of justifications and defenses for the proposed management strategies (see ACAG, 2005) and falls far short of DEFRA's aspiration to "make a clear transition away from defending current decisions to more participation by the public in the overall decision making process" (DEFRA, 2007, 15). DEFRA would be wise to draw on its more successful management experiences in Slapton Sands and Felpham in order to achieve the desired "clear transition" away from the almost exclusively "top-down" style of management strategy that currently exists. It would be even wiser to acknowledge that, rather than involving a move from "top-down" to "bottom-up" management, the practice of community-based environmental planning and decision-making should seek to harness the benefits of local knowledge and participation within the broader framework of state policy and action (Lane \& McDonald, 2005). This assumes, however, that the state practices the policy it is preaching, or at least that its policies do not conflict and 
undermine each other-an assumption that is arguably not met where the Government's landuse planning policy is concerned.

\section{Land-Use Planning Policies}

The land-use planning system in England and Wales spans national, regional, and local levels. Local planning authorities have the power to control land development (including coastal development) at the local level by making decisions on planning applications (DEFRA, 2006a).

The plight of locals along the North Norfolk coastline who may soon find themselves without homes or businesses is partly a result of poor Government policy, in the sense that planning policies have allowed (and are still permitting) homes and businesses to be built in these high risk coastal areas. The Department for Communities and Local Government has recently released PPS25, a new Planning Policy Statement on development and flood risk, to clarify, strengthen, and replace the previous planning policy (DCLG, 2006). During the consultation process, DEFRA (2006a) suggested that PPS25 would make SMPs a "material consideration" for future development plans on the coast. Disappointingly, the recently published policy only mentions SMPs twice, when recommending that land-use planning policies "be consistent with" and "informed by" SMPs (DCLG, 2006). There is no requirement to provide reasons for planning decisions that may be inconsistent with SMPs. The weakness of these recommendations in the new PPS25 coupled with the ability (and inclination) of land-use planning authorities to ignore recommendations of management plans in issuing planning consents (Belfiore, 2003; French, 2004) suggest that PPS25 may not in fact make that much difference in practice.

Similarly, DEFRA's guidance on how the SMP process and coastal groups can support the landuse planning process in discouraging inappropriate coastal development (DEFRA, 2006a) really only pays lip-service to the importance of integrating the concerns and advice of coastal planners and SMPs into this planning process. Local planning authorities must simply "take account" of such advice, rather than being required to provide the reasons for, or the consequences of, a decision to proceed with planning practices that contradict and undermine such advice.

Just over 100 miles south of North Norfolk, the on-going Thames Gateway development in East London's Lower Lea Valley (which includes the construction of up to 40,000 new homes on a floodplain) is a concrete example of the unilateral power of the planning authorities to proceed with a risky development regardless of the concerns of coastal planners or other advisory bodies. A 2005 Strategic Flood Risk Assessment of the area concluded that "in East London the consequence of the Thames Tidal Defences (TTD) failure would be very large and needs to be investigated further" (Thames Gateway London Partnership, 2005, 18). Yet the development is still going ahead, its stated aim (ironically) being to provide a "sustainable and enduring legacy" (http://www.london.gov.uk/mayor/planning/docs/lowerleavalley-pt1.pdf). 


\section{The Case for Compensation}

It is doubtful whether the quantum leap "to make a clear transition away from defending current decisions to more participation by the public in the overall decision making process" (DEFRA, 2007, 15) will be made without affording compensation to those North Norfolk minority communities who will lose their homes, businesses and have to suffer relocation as a result of coastal management policy (Figure 3).

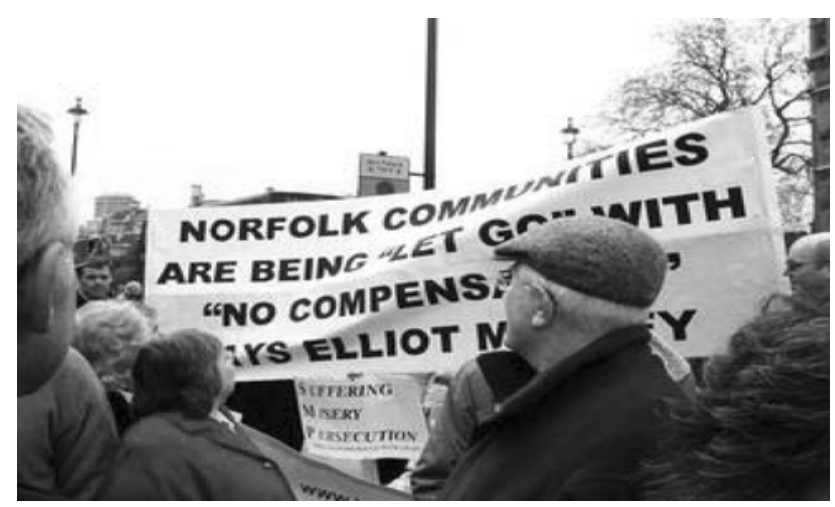

Figure 3. Norfolk communities are being "let go" with "no compensation" says Elliot Morley (CCAG, 2006).

A discussion paper (DEFRA, 2004, 2) prepared by DEFRA's Flood Management Division in relation to the "Making Space for Water" strategy recognises that "[c]ompensation and relocation issues ... form an essential part of an integrated approach to flood and coastal erosion risk management." Yet it is difficult to find concrete examples of this sentiment in current Government policy. There have been piecemeal gestures toward payment of compensation for losses due to flooding and coastal erosion: the Minister of State for Climate Change and the Environment recently confirmed that agri-environment funding is currently available to farmers and landowners to "farm water" as part of a managed realignment scheme (http://www.publications.parliament.uk/pa/cm200607/cmhansrd/cm061206/halltext/61206h0 003.htm). Unfortunately this has only served to increase the inequities in the system as it leads to the logical argument that such payments should also be extended to property owners. It is unfortunate that consideration has not yet been given to solutions such as redirecting the funds available for maintaining current defenses to buy out property on under-developed stretches of coastline where a no active intervention policy has been proposed (as in North Norfolk), or providing incentives for local communities to establish and start contributing to a local relocation fund to which the Government could contribute on a pro-rata basis. Drawing an analogy with the UK tax-system, which already makes several socially accepted distinctions between main and secondary residences for the purposes of tax payments and exemptions, another possibility could be to limit compensation to owners of principal private residences (and local businesses), thus excluding multi-home-owners. This would have the advantage of reducing the burden on public funds while affording recognition to the plight of those who lose their primary homes and businesses to flooding and coastal erosion. 
Self-defense and insurance against flooding and erosion risks may not be affordable for everybody (Stallworthy, 2006). This social injustice is compounded by the possibility of compensation being afforded to more affluent individuals who are prohibited from carrying out their own coastal protection measures (DEFRA, 2004). Although social justice issues are outside the scope of SMPs, dealing with these issues in parallel with the development of the second generation of SMPs would arguably facilitate acceptance of the more "difficult" shoreline management policies. It is encouraging to see that the Minister of State for Climate Change and the Environment has recently called for dialogue on coastal erosion compensation with regard to communities such as those in North Norfolk (http://www.coastnet.org.uk/?a 10,1\&u 12). Hopefully the importance of this dialogue will be recognized and facilitated in the future, particularly in light of the role played by the Government's land-use planning policies in the creation of the currently prevailing social inequities.

\section{Conclusion}

The revised Kelling to Lowestoft-Ness SMP recognizes the dynamic nature of the North Norfolk coastline by advocating policies of managed realignment and no active intervention for much of this coastline. The fact that the wider implications of current management strategies are not yet fully understood highlights the importance of management decisions being informed by current research. Although DEFRA has attempted to avoid burdening future generations with the cost of maintaining unsustainable defenses by trying to implement a long-term vision for a sustainable coast through working with, rather than against, coastal processes, the establishment of a long-term vision is not, in itself, sufficient. In order to reap the benefits of the adaptive management framework proposed by the Kelling to Lowestoft-Ness SMP, the Government should revise its practices and policies in relation to land-use planning, compensation, and stakeholder engagement in the coastal management process.

The on-going Thames Gateway development suggests that the land-use planning system rather than the presence or absence of a compensation and relocation policy is the true root of the problem of continuing inappropriate development. The need for improved links with the planning system merits more than the lip-service accorded to it by the Government's new Planning Policy Statement on development and flood risk. A more robust approach would place the onus on land-use planning authorities to provide a publicly-available reasoned case for noncompliance with SMP policy

Amid the cries for meaningful community-based involvement in addressing flooding and coastal erosion problems, it is important to remember that public interest has a place. According the notion of public (as opposed to community) interest in coastal management more importance could help pave the way toward a compensation policy that involves some element of public funding; likewise a (partly) publicly funded compensation policy would validate a general public interest in coastal management as the taxpayer would have a financial stake in such management. Social impact assessment and compensation considerations should form part of the long-term strategic management of the coastline. 
An adaptive management strategy, if successfully applied in the context of revised Government practices and policies, has the potential to gradually change perceptions of the need for protection of the North Norfolk coastline and thus influence the shape of the overall vision for this complex coastline.

\section{References}

ACAG 2004. The Kelling to Lowestoft Shoreline Management Plan, Anglian Coastal Authorities Group. Available athttp://www.northnorfolk.org/acag/default smp.asp. Accessed April 22, 2007.

ACAG 2005. The Kelling to Lowestoft Shoreline Management Plan, Response to Consultation, Anglian Coastal Authorities Group. Available at http://www.happisburgh.org.uk/content/SMP Consultation Response.doc. Accessed April 22, 2007.

Belfiore, S. 2003. The growth of integrated coastal management and the role of indicators in integrated coastal management: Introduction to the special issue. Ocean \& Coastal Management 46:225-234.

Blackwell, M. S. A., D. V. Hogan, and E. Maltby. 2004. The short-term impact of managed realignment on soil environmental variables and hydrology. Estuarine, Coastal and Shelf Science 59:687-701.

Bray, M., J. M. Hooke, and D. Carter. 1997. Planning for sea-level rise on the south coast of England: Advising the decision-makers. Transactions Institute of British Geographers 22:13-30.

Bridges, E. M. 1998. Classic landforms of the North Norfolk coast, Sheffield: The Geographical Association.

Brooke, J. S. 1992. Coastal defence: The retreat option. Journal of the Institute for Water and Environmental Management 6:151-157.

Burgess, K., J. D. Orford, K. Dyer, I. Townend, and P. Balson. 2002. Futurecoast-The integration of knowledge to assess future coastal evolution at a national scale. In Proceedings 28th International Conference on Coastal Engineering, ASCE, 3221-3233 p.

CCAG 2006. Coastal Concern Action Group. Available at http://www.happisburgh.org.uk/ content/consultation response/. Accessed April 22, 2007.

Coates, T., A. Brampton, and K. Powell. 2001. Shingle beach recharge in the context of coastal defence: Principles and problems. In Ecology and geomorphology of coastal shingle, eds. J. R. Packham, R. E. Randall, R. S. Barnes, and A. Neal, 394-402. Otley: Westbury Academic and Scientific Publishing. 
Cooper, N. J., and H. Jay. 2002. Predictions of large-scale coastal tendency: Development and application of a qualitative behaviour. Journal of Coastal Research 36:173-181.

DCLG 2006. Planning Policy Statement 25: Development and Flood Risk. Available at http://www.communities.gov.uk/index.asp?id 1504639. Accessed April 22, 2007.

DEFRA 2004. Flood Management Division Background Paper. Payment of Compensation, Relocation and Other Issues in relation to Flood and Coastal Erosion Risk Management. Available at http://www.defra.gov.uk/environ/fcd/policy/strategy/comp.pdf. Accessed April 22, 2007.

DEFRA 2006a. Shoreline Management Plan Guidance, Volumes 1 and 2, Department for Environment, Food and Rural Affairs. Available at http://www.defra.gov.uk/environ/fcd/policy/smp.htm. Accessed April 22, 2007.

DEFRA 2006b. Making Space for Water: Taking forward a new Government strategy for flood \& coastal erosion risk management, Department for Environment, Food and Rural Affairs. Available at http://www.defra.gov.uk/environ/fcd/policy/strategy.htm. Accessed April 22, 2007.

DEFRA 2007. Making Space for Water, Quarterly Update March 2007Department for Environment, Food and Rural Affairs. Available at http://www.defra.gov.uk/environ/fcd/policy/strategy/update2.pdf. Accessed April 22, 2007.

French, P. W. 2004. The changing nature of, and approaches to, UK coastal management at the start of the twenty-first century. Geographical Journal 170:116-125.

Futurecoast 2002. Final Project Report, DEFRA. Available at http://www.defra.gov.uk/environ/ fcd/futurecoast.htm. Accessed November 22, 2006.

Hooke, J. 1998. Issues and strategies in relation to geological and geomorphological conservation and defence of the coast. In Coastal defence and earth science conservation, ed. J. Hooke, 1-9. Oxford: The Geological Society.

Lane, M. B., and G. McDonald. 2005. Community-based environmental planning: Operational dilemmas, planning principles and possible remedies. Journal of Environmental Planning and Management 48:709-731.

Ledoux, L., S. Cornell, T. O'Riordan, R. Harvey, and L. Banyard. 2005. Towards sustainable flood and coastal management: Identifying drivers of, and obstacles to, managed realignment. Land Use Policy 22:129-144. 
MAFF 2000. A review of shoreline management plans 1996 to 1999. Final Report March 2000. A report produced for the Ministry by a consortium led by the Universities of Newcastle and Portsmouth.

Mee, L., J. Friedrich, and M. Gomoiu. 2005. Restoring the Black Sea in times of uncertainty. Oceanography 18:100-111.

Mo“Iler, I., T. Spencer, J. R. French, D. J. Leggett, and M. Dixon. 2001. The sea-defence value of salt marshes: Field evidence from North Norfolk. Journal of Chartered Institute of Water and Environmental Management 15:109-116.

Murdock, A., R. Home, M. Harrison, and A. Hosking. 2001. The prediction of future coastal evolution for Shoreline Management Plan (SMP) Reviews: The Futurecoast Project. In Proceedings of the AGI Conference, GIS, 1-7 p.

Myatt-Bell, L. B., M. D. Scrimshaw, J. N. Lester, and J. S. Potts. 2002. Public perception of managed realignment: Brancaster West Marsh, North Norfolk, UK. Marine Policy 26:45-57.

Orford, J., and S. Jennings. 1998. The importance of different time-scale controls on coastal management strategy: The problem of Porlock gravel barrier, Somerset, UK. In Coastal defence and earth science conservation, ed. J. Hooke, 87-103. Oxford: The Geological Society.

Stallworthy, M. 2006. Sustainability, coastal erosion and climate change: An environmental justice analysis. Journal of Environmental Law 18:357-373.

Taylor, J. A., A. P. Murdock, and N. I. Pontee. 2004. A macroscale analysis of coastal steepening around the coast of England and Wales. Geographical Journal 170:179-188.

Thames Gateway London Partnership 2005. Strategic Flood Risk Assessment of East London, Entec UK Limited in collaboration with JBA Consulting. Available at http://www.thamesgateway.org.uk/uploadedFiles/projects/Environment_and_Quality_of_Life/SFRA\%20Report\%20 Appendix\%20-\%20Flood\%20Risk\%20Analysis.doc. Accessed April 23, 2007.

Walker, B., S. Carpenter, J. Anderies, N. Abel, G. Cumming, M. Janssen, L. Lebel, J. Norberg, G. D. Peterson, and R. Pritchard. 2002. Resilience management in social-ecological systems: A working hypothesis for a participatory approach. Conservation Ecology 6(1):14. Available at http://www.consecol.org/vol6/iss1/art14. Accessed April 26, 2007. 